\title{
COMPARATIVE GENETICS OF DROSOPHILA PROSALTANS
}

\author{
B. SPASSKY, S. ZIMMERING and TH. DOBZHANSKY \\ Columbia University, New York
}

I. INTRODUCTION

Received 25.xii.49

THE architecture of the germ plasm undergoes changes in the process of evolution. The genes become altered by mutation, and their arrangement in the chromosomes is modified by structural change. Comparison of the genetic maps of chromosomes in related species is one of the methods of studying the evolution of the germ plasm. Species of Drosophila are favourable for such studies, and about ten of them have been investigated in more or less detail. It appears that the degree of divergence in systematic characters is not very strongly correlated either with the amount of gene differentiation, or with divergence in the gene arrangement. The information now available is, however, insufficient to give a clear idea about the mutual relationships of the various classes of changes that are observed. More data is obviously necessary. No species of the saltans group of the subgenus Sophophora has been studied. Since 1944, we have collected mutants and examined the linkage relationships in Drosophila prosaltans Duda, which is a member of this group. The results are reported in the present article.

\section{MATERIAL AND METHOD}

The distribution of $D$. prosaltans extends from the subtropical zone of Central Mexico to Paraguay and Southern Brazil (states of São Paulo and Paraná). Within this region, the species occurs rather sporadically; it is common only in some localities on the island of Marajó in the delta of the Amazon, and near Imperatriz, in the state of Maranhãó, Brazil. Adult flies can be collected on fallen fruit in the forest. They are attracted to fermenting banana traps, especially in advanced stages of fermentation, but they are rarely met with in human dwellings (Dobzhansky and Pavan, unpub.). In the laboratory, the species breeds well on standard food media, and is favourable material for studies on comparative genetics.

Except where otherwise specified, a strain derived from a single female collected at Belem, state of Pará, Brazil, was used in the experiments. Some mutants arose spontaneously in the course of the work, but most of them were found in the progeny of flies treated with X-rays. Young males were given $4000 r$-units of X-rays, and 
outcrossed to untreated females, using 3-5 pairs of flies per culture. The $F_{1}$ flies were examined for dominant mutants. Then two or three small mass cultures, with about 4 pairs of flies, were made from each $F_{1}$ bottle, and the $F_{2}$ and $F_{3}$ flies were examined for sex-linked and autosomal-recessive mutants. All the experiments were carried out at room temperature or in incubators at $25^{\circ} \mathrm{C}$. The X-ray treatments were administered by Drs L. D. Marinelli and E. Focht of the Memorial Hospital in New York, to whom the authors wish to express their gratitude.

\section{SEX-LINKED MUTANTS}

cut $(c t)$.- In an X-rayed culture, 29th April 1947. Recessive. All wing margins cut, making the wing narrow and acuminate at the distal end, lancet-like in shape. This shape resembles the wing of the autosomal dominant mutant Blade of $D$. pseudoobscura. Among the cut alleles in $D$. melanogaster, it resembles most cut ${ }^{6}$ (fig. 14 in Morgan, Bridges and Sturtevant, 1925) but is more acuminate.

Eyeless (Ey).- In an X-rayed Guatemala strain, 16th April 1944. Dominant, lethal in the male. Eyes variable in size from normal to no eye at all. Asymmetrical expression very frequent, including extreme cases when a normal eye is present on one side and none on the other. The eye surface normal, not rough when eye is large, but the eye may be misshapen when its size is much reduced. Antennæ deformed or reduplicated in some flies. In some completely eyeless individuals, the front and the vertex are also reduced and warped. This mutant seems to be a good parallel to the dominant mutant Eyeless in the fourth chromosome of D. melanogaster.

facet $(f a)$. -1 $3^{\text {th }}$ March 1947, in an X-rayed culture. Recessive. Eyes uniformly rough, the roughness being more pronounced in males than in homozygous females. Analogy with facet in $D$. melanogaster uncertain. An allelic mutant was found on 15th March 1944, in the offspring of an X-rayed father; this proved to be connected with a translocation between the $\mathrm{X}$ and the second chromosomes.

garnet $(\mathrm{g})$ - - $3^{\text {th }}$ April 1947, in an X-rayed culture. Recessive. Eye colour in young flies between vinaceous-rufous and Hay's russet (Ridgway, plate XIV), darkens slightly with age. Testes very pale yellow. Malpighian tubes almost completely clear, larval Malpighian tubes clear. The compound garnet-sepia differs little from garnet. May or may not be analogous to garnet in $D$. melanogaster.

grooveless (gvl). - 27th April 1947, in an X-rayed culture. Recessive. The depression normally present along the suture dividing the scutellum from the thorax almost completely obliterated. The flies usually have black pigmented scars on the sides of the scutellar suture or above the humeral callus, or on the pleuræ behind the sternopleural bristles. The scars are, as a rule, asymmetrical. In the young flies, they contain a liquid which is probably blood. These scars arise from blisters that are formed in certain parts of the integument which are filled with blood during the hatching from the pupa. An excellent parallel to grooveless in the fourth chromosome of $D$. melanogaster.

miniature $(m)$. 27th April 1947, in an X-rayed culture. Recessive. 
Wings decreased in size but the proportions are only slightly different from normal (slightly narrower). The density of wing hairs increased, which indicates a reduction in cell size. An excellent parallel to miniature in D. melanogaster.

Notch $(\mathcal{N})$.- February 1944, in an X-rayed culture. Dominant, lethal in the male. Wing veins thickened and expanded into small deltas at the wing margins. A strong notch on the first section of the costa making the wing narrow at the base, and sometimes small notches between the ends of the third and fourth veins. Acrostichal bristles normal, but the inner longitudinal dark bands on the thorax constricted or even interrupted at the level of the central spot. This mutant differs considerably in appearance from Notch in $D$. melanogaster, and yet it has enough common features to be regarded as a good analogue. Recurrences of Notch observed on 27th April 1947 and ist April 1948, in X-rayed strains.

Prune $(P n)$.- February 1948 , in an X-rayed culture. Dominant, lethal in the male. Eyes in young flies between Ridgway's garnet-brown (plate I) and Madder brown (plate XIII). The colour darkens with age to dark sepia. This mutant has no good analogues among mutants in other species.

sable (s). - I 7th April 1947, in an X-rayed culture. Recessive. Body colour much darker than normal, shiny blackish brown. The peculiar polished appearance, resembling the effect obtained when the fly is covered with oil, is particularly noticeable on the pleuræ of the thorax. The colour pattern of the thorax, which is characteristic of the species, is reduced to indistinct dark stripes. A doubtful analogue of sable in $D$. melanogaster.

scalloped $(s d)$. - I $4^{\text {th }}$ January 1947 , in an X-rayed culture. Recessive. The anterior, distal, and posterior wing margins nicked to varying extents in different individuals. More extreme in males than in females. The wing veins in some flies thickened and darkened in the proximal two-thirds of the wing. Resembles beaded of $D$. pseudonbscura as well as scalloped of D. melanogaster.

scute (sc). -5 th May 1948 , in an X-rayed culture. Recessive. All four scutellar bristles absent, other bristles normal. Connected with a chromosomal aberration which suppresses recombination in the $\mathrm{X}$ chromosome. Probably analogous to scute in $D$. melanogaster.

sepia (se).-2oth April 1947, in an X-rayed culture. Recessive. Eye colour purplish-sepia, translucent in young flies, darkens with age. Colour of testes in aciults normal. Colour of Malpighian tubes in adults and larvæ normal. A good analogue of sepia in D. melanogaster. An allelic mutant found on 29th April 1947, also from an X-rayed culture.

Shortened $(S h)$. - I $5^{\text {th }}$ January 1947 , in an X-rayed culture. Dominant, lethal in the male. The second longitudinal vein reduced distally or even wholly absent. In some flies, a section of the vein unconnected either proximally or distally is present in place of the proximal third of the normal second vein. Other veins normal. No analogue among sex-linked mutants in D. melanogaster.

singed $(s n)$.-2oth March 1944, in an X-rayed strain from Iporanga, Brazil. Recessive; homozygous female sterile. All bristles short and strongly singed or curled. Acrostichal and other hairs short, stubby, and bent or curved. Body colour slightly darker and colour pattern of thorax less distinct than in normal flies. A good parallel of the most extreme known alleles of singed in $D$. melanogaster. A recurrence of singed observed 
on I8th July I944, in the Belem strain, but this mutant possessed poor viability and was lost.

vesiculated (vs).-29th April 1947, in an X-rayed culture. Recessive. Wings blistered, warped or crumpled, frequently asymmetrical. The wings vary from spoon-shaped but normal in size to crumpled small rudiments. Young flies usually have large blisters filled with blood. A fair analogue of vesiculated in $D$. melanogaster.
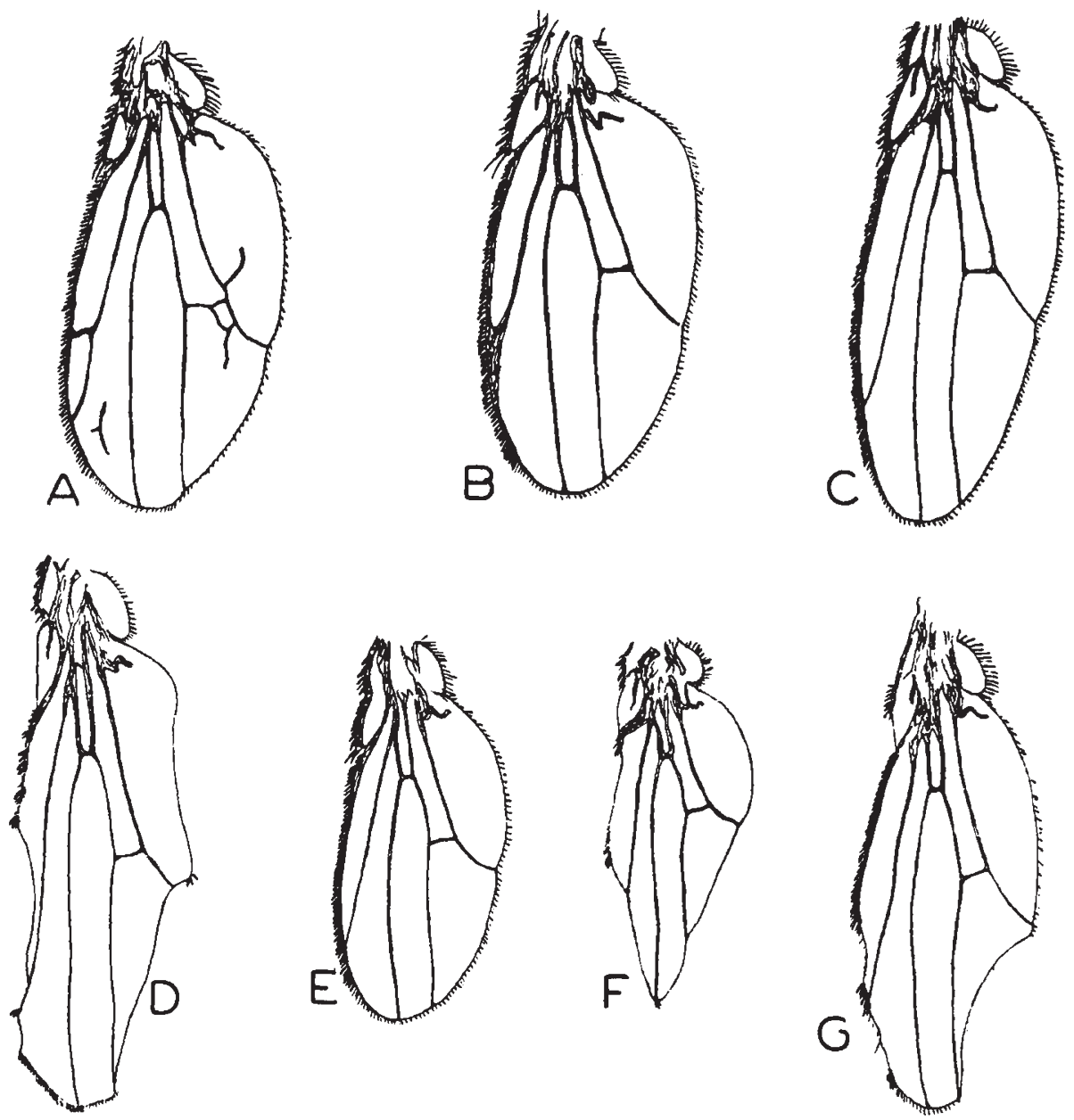

Fig. I.-Some of the wing mutants in Drosophila prosaltans. A-plexus ; B-Delta ; C-Blade ; D-Beaded ; E-miniature ; F-miniature-cut ; G-scalloped. The magnification is similar in all cases.

white $(w)$ - $13^{\text {th }}$ July 1944 , in an X-rayed culture. Recessive. Eyes clear white. Testes and Malpighian tubes in adults and larvæ colourless. An excellent analogue of white in D. melanogaster.

yellow $(y) .-28$ th July 1944 , found by Mr G. Streisinger. Spontaneous. Body colour dirty greyish yellow, almost Ridgway's clay colour or tawny olive (plate XXIX). The colour pattern on the thorax characteristic for the species is indistinct. An excellent analogue of yellow in D. melanogaster. 


\section{MUTANTS OF THE SECOND LINKAGE GROUP}

Beaded $(B d)$. - I 7 th August 1947, in the Eyeless strain. Spontaneous. Dominant, lethal when homozygous. Wings narrow and pointed at the tips ; the reduction in width is due to numerous excisions both at the costal and posterior margins. Tufts of the bristles on the costal margin preserved in some individuals, the costa is almost gone in others. The third and fourth veins preserved. A fair parallel of Beaded in D. melanogaster.

Curly $(C y)$. - 16 th June 1944 , in an X-rayed culture of a strain from Bertioga, Brazil. Dominant, lethal when homozygous. Wings curved upward and outward. Manifestation variable, some flies being close to normal except for a wavyness of the wing blade, especially in the distal half. When strongly pronounced, the wing is curled $360^{\circ}$. Except when in compounds with plexus, no blisters are found (as in D. pseudoobscura) and no segmentation apparent in the wing veins (as in Curly of D. melanogaster) ; otherwise an excellent parallel to the similarly named mutants in those species.

Engrailed $\left(E_{n}\right)$. - 7th January 1948, in an X-rayed culture. Dominant, lethal when homozygous. Wings shortened, constricted at the base, and broadly rounded at the apex. The scutellum with a median nick or cleft on the posterior margin; the posterior scutellar bristles usually shortened and frequently bent hook-shaped. This mutant has traits in common with the recessive engrailed of $D$. melanogaster and also with some alleles of vestigial in the same species.

grooved ( $g r v$ ). -6th March 1947, in a culture of Plum of Guatemala origin. Probably a spontaneous mutant. Thorax shortened and broadened, with grooves or nicks on the anterior margin, situated at the anterior ends of the inner parts of the dark stripes normally present in this species on the thorax. Scutellum short and broad, slightly bulging. Abdomen very slightly broadened. Seems not to resemble known mutants in other species.

Groundoff $(G f)$.- July 1944, in an X-rayed culture of Guatemala origin. Posterior part of the eye with normal facet structure destroyed, as though ground off with a file; the altered part of the eye covered with a glassy cuticle. Expression more extreme at high temperature, almost suppressed at $18^{\circ}$. The flies with least expression have normal eyes with only a few facets or groups of facets missing near the posterior eye margin. Progressive increase of the manifestation results in a greater and greater portion of the posterior part of the eye affected, up to the posterior two-thirds in heterozygotes. The boundary between the affected and unaffected parts of the eye usually very sharp. Homozygotes usually die but some of them hatch as weak flies with the entire eye affected as described above. No parallel in other species.

Lobe $(L)$ - - 3rd March 1947, in an X-rayed culture. Dominant, lethal when homozygous. Eyes reduced in size and strongly roughened. The reduction variable and often asymmetrical. The extreme manifestation mimics the homozygous Bar eye in $D$. melanogaster to a remarkable extent. Less extreme variants resemble more the Lobe mutant in the species just named, since they have kidney-shaped or triangular eyes which are often deformed or lobed. A side effect sometimes present is the branching of the wing veins.

plexus $(p x)$. - 25th March 1947, in an X-rayed culture. Recessive. Wing veins branched or isolated sections of the veins present in the cells 
where normally none are found. Particularly frequent are : a crossvein between the second longitudinal and the costal veins, not far from the end of the former; an isolated vein section in the distal part of the submarginal cell ; a branching of the posterior crossvein which may develop into a vein which divides the second posterior cell into two parts; and a recurrent vein in the third posterior cell which almost joins the anal vein. The mutant Star acts as a semi-suppressor of plexus. A fair parallel of plexus in $D$. melanogaster and $D$. pseudoobscura.

Plum $(P m)$.- June 1944, in an X-rayed Guatemala strain, and in the same month, a recurrence was observed in an X-rayed Belem strain. Dominant, lethal when homozygous. In young flies, the eye brick-red (Ridgway, plate XIII) in colour, with traces of mosaicism; darkening with age leads to eyes of about the Hessian brown colour (Ridgway, plate XIII) and to the mosaicism being no longer noticeable. Testes yellow with transparent mosaic spots, Malpighian tubes apparently uniformly pigmented. The Plum mutant in the Belem strain is associated with a powerful crossing over suppressor, the Guatemala one seems to be free of suppression. A good parallel to Plum in D. melanogaster.

Star $(S) .-27_{\text {th }}$ March 1947, in an X-rayed strain. Dominant, lethal when homozygous. Eyes large, strongly roughened. Exerts a suppressor effect on the mutant plexus (see above). A fair parallel to Star in $D$. melanogaster.

\section{MUTANTS OF THE THIRD LINKAGE GROUP}

abdomen rotatum (ar).-August 1947, in an X-rayed strain. Recessive. Abdomen twisted clockwise through about $45^{\circ}$. Males sterile, females fertile. Viability good. A good parallel to abdomen rotatum in $D$. melanogaster.

Blade $(B l d)$.- February I 944, in an X-rayed strain of Bertioga (Brazil) origin. Dominant, lethal when homozygous. Wings held out at right angles to the thorax ; the shape of the wing is normal or slightly narrower than normal, sometimes unexpanded but frequently folded lengthwise or in general irregular. Resembles Dichæte in $D$. melanogaster but bristles are normal.

crossveinless $(c v)$.-March 1947 , in cultures which had not been recently X-rayed. Recessive. Both anterior and posterior crossveins missing or interrupted. Variable, but apparently does not overlap wild-type, since at least one of the crossveins shows interruption in all specimens. Frequently asymmetrical. Not classifiable in compound with the Delta mutant. A good parallel to crossveinless-C in D. melanogaster.

Delta $(\Delta)$.-A frequently recurrent mutant in X-rayed cultures. Dominant, lethal when homozygous. Wing veins thickened at the margin. Crossveins sometimes thickened. Eyes slightly rough. In weaker alleles, sometimes only the second longitudinal vein expanded in the distal portion and fused with the costal margin, so that the costal index is very radically altered. A good parallel of Delta in D. melanogaster.

hunchback (hu).-14th March I947, in an X-rayed culture. Recessive. Thorax and scutellum short and broad, strongly convex. The groove along the suture separating the scutellum from the thorax deep. Wings curved upward or wrinkled. Variable, but does not overlap wild-type. The thorax characters are more constant than those of the wings. 
Spread $(S p d)$. - I I th August 1947, in an X-rayed culture. Dominant, lethal when homozygous. Wings held out at right angles from the thorax, somewhat shorter and broader than normal ; frequently warped downwards.

TABLE I

Summary of linkage data. Three point crosses

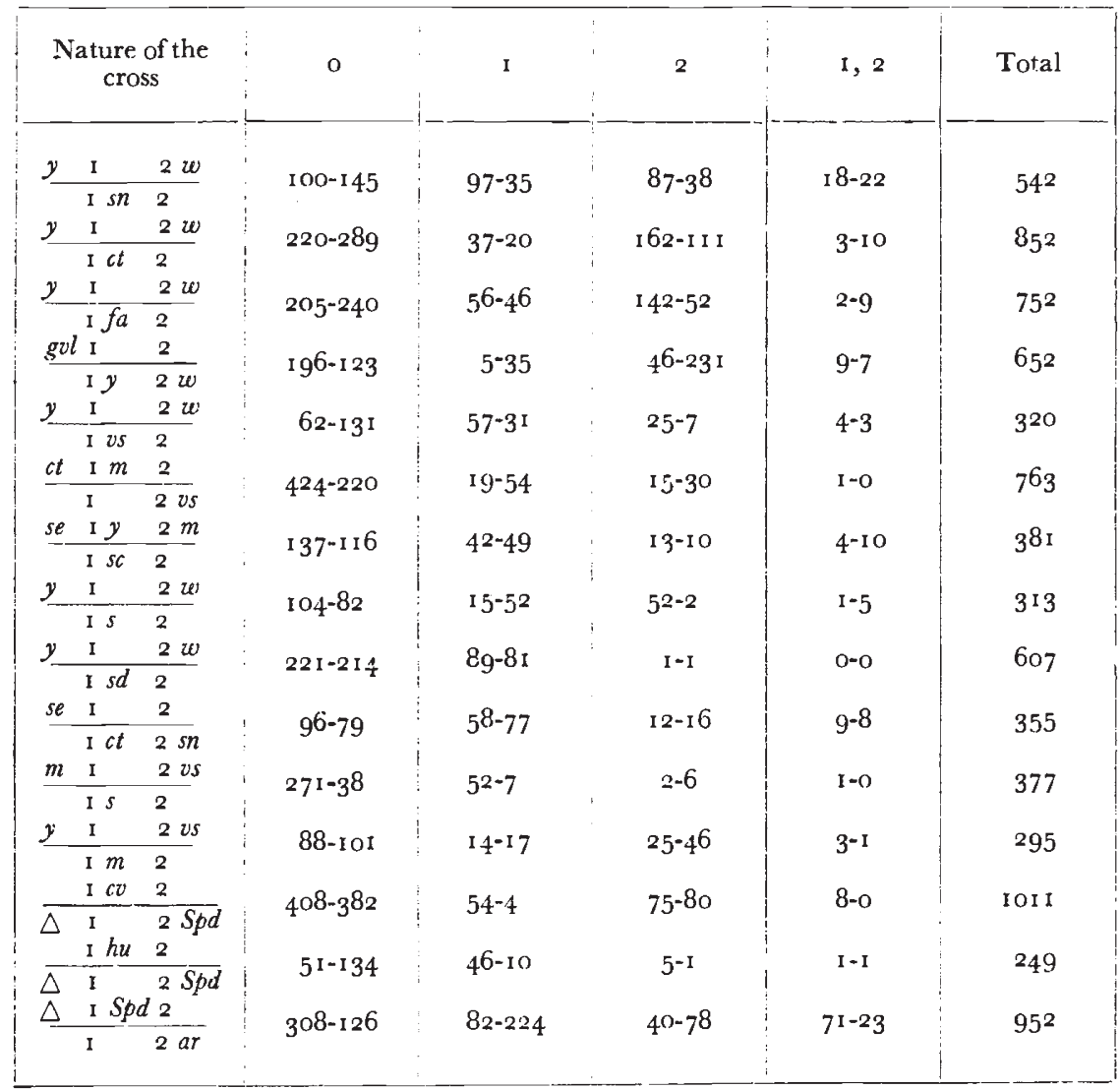

Aristapedia (Arp).-8th November 1947, in an X-rayed culture. Dominant, viability poor even in heterozygous condition, lost. An extreme aristapedia-like change with aristæ transformed into a leg-like organ.

\section{LINKAGE MAPS}

Drosophila prosaltans has three pairs of chromosomes; the $\mathrm{X}, \mathrm{Y}$, and second chromosomes are large and metacentric, the third chromosome is slightly more than half as long as the others and acrocentric. In accordance with this, three linkage groups have been found. The largest of them consists of 17 sex-linked genes, which must be carried in the $\mathrm{X}$-chromosome. The second linkage group contains 9 genes and the third contains 7 genes. Prof. A. G. L. Cavalcanti (unpub.) has examined the chromosomes in the salivary 
gland cells of some of our mutants which were known to be associated with structural changes and proved that the second linkage group is borne in the metacentric, and the third linkage group is borne in the acrocentric autosomes.

TABLE 2

Summary of linkage data. Four point crosses

\begin{tabular}{|c|c|c|c|c|c|c|c|c|c|c|c|c|}
\hline \multicolumn{4}{|c|}{$\begin{array}{c}\text { Nature of the } \\
\text { cross }\end{array}$} & \multirow{3}{*}{$693-654$} & \multirow{3}{*}{$242-209$} & \multirow{3}{*}{$\begin{array}{c}2 \\
-132-1 \text { I9 }\end{array}$} & \multirow{2}{*}{$\begin{array}{c}3 \\
\text { I0-I I }\end{array}$} & \multirow{2}{*}{$\begin{array}{l}\text { I, } 2 \\
6-4\end{array}$} & \multirow{2}{*}{$\begin{array}{l}\mathrm{I}, 3 \\
\mathrm{I}-5\end{array}$} & \multirow{2}{*}{$\begin{array}{l}2,3 \\
- \\
10-5\end{array}$} & \multirow{2}{*}{$\begin{array}{c}1,2, \\
3 \\
1-2\end{array}$} & \multirow{2}{*}{$\underbrace{\text { Total }}_{2104}$} \\
\hline$y$ & I & 2 & $3 w$ & & & & & & & & & \\
\hline & I $c t$ & $2 s n$ & 3 & & & & & & & & & \\
\hline & I $\mathrm{ct}$ & 2 & $3 s n$ & $282-301$ & $88-02$ & $49-44$ & $I-3$ & $2-1$ & $0-0$ & $0-0$ & $0-0$ & 863 \\
\hline$y$ & I fa & $2 m$ & 3 & & & 4944 & & & & & & \\
\hline$y$ & I & $2 v s$ & 320 & $77-126$ & $32-11$ & $3^{6-17}$ & $26-20$ & $4-3$ & I -6 & $2-1$ & $0-0$ & 362 \\
\hline se & I $y$ & $2 m$ & 3 & $20-57$ & $0-22$ & $10-12$ & $2-28$ & I6-20 & $21-22$ & $0-2>$ & $0-2$ & קאו \\
\hline & I & 2 & $3 g$ & $120-51$ & $10-33$ & $10-12$ & & 10.23 & $2-23$ & $0-3$ & $0-2$ & 300 \\
\hline se & I & $2 y$ & $3 m$ & $162-109$ & $63-125$ & $4 \mathrm{I}-\mathrm{I} 7$ & $45-47$ & I $2-25$ & $23-34$ & & $0-5$ & 732 \\
\hline & I $g v l$ & & 3 & $102-10 y$ & $0,3-125$ & 410 & $45-41$ & $12-25$ & 23.34 & $13-11$ & & $73^{2}$ \\
\hline & I & $2 g$ & 3 & $327-401$ & 37-86 & $46-104$ & $3-43$ & $2-I$ & $4-6$ & $5-4$ & $0-0$ & 1179 \\
\hline$y$ & I $m$ & 2 & $3 v s$ & & & & .040 & & & $\boldsymbol{J}$ & & $11 / 9$ \\
\hline$y$ & I $m$ & 2 & $3 w$ & $230-3^{8} 5$ & $90-63$ & $104-81$ & $?-93$ & $2-3$ & $?-12$ & $0-3$ & $0-0$ & I 066 \\
\hline & I & $2 g$ & 3 & & & & & & & & & \\
\hline & I & 2 & $3 P n$ & $95^{-25}$ & I 2-O & $4^{2-5}$ & $43-7$ & $6-8$ & I -0 & $0-0$ & $0-0$ & 244 \\
\hline get & I $y$ & $2 m$ & 3 & & & & & & & & & \\
\hline & I & $2 B d$ & $3 C y$ & $479-74^{8}$ & $299-196$ & I 2-3 & $203-179$ & $0-7$ & $6-31$ & $4^{-1} 5$ & I -4 & 2187 \\
\hline & $\begin{array}{l}\text { I } p x \\
\text { I } P m\end{array}$ & $\begin{array}{r}2 \\
22\end{array}$ & $\begin{array}{l}3 \\
3\end{array}$ & & & & & & & & & \\
\hline & I & $2 S$ & $3 B d$ & $185-160$ & $0-11$ & $12-28$ & $5^{2-46}$ & $4-3$ & $0-3$ & $0-8$ & $I-I$ & 520 \\
\hline
\end{tabular}

TABLE 3

Summary of linkage data. Five point crosses

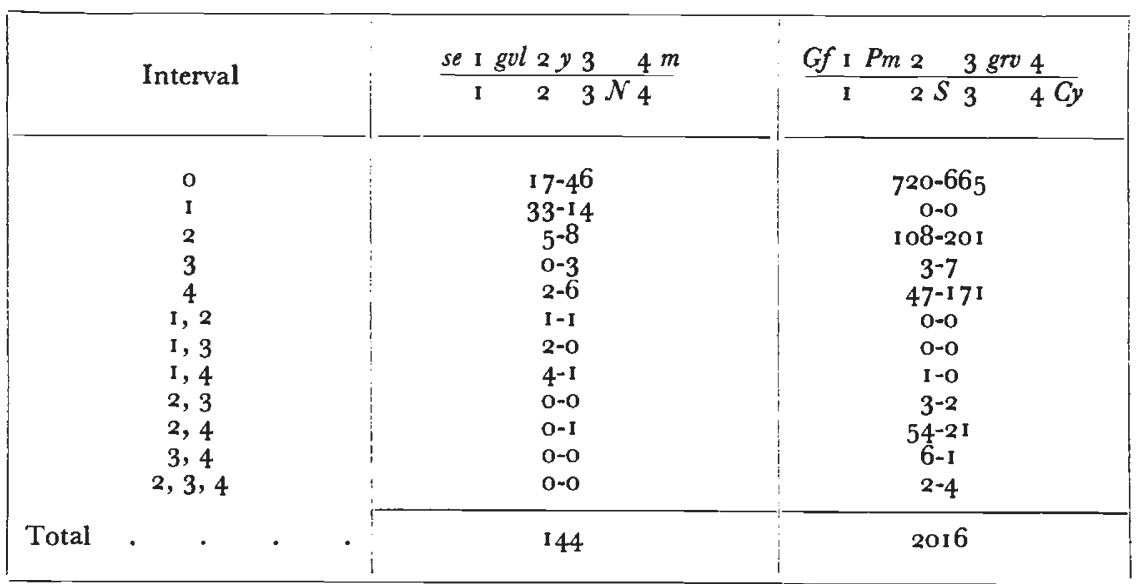

Tables I-3 report the results of linkage experiments in which at least three genes of the same linkage group were involved. The numbers of the flies in the two complementary classes are given for 
each interval ; a convention is followed of giving first the class which contains the gene indicated on the left above the line in the formula describing the nature of the cross. The data are summarised in the form of linkage maps in fig. 2.

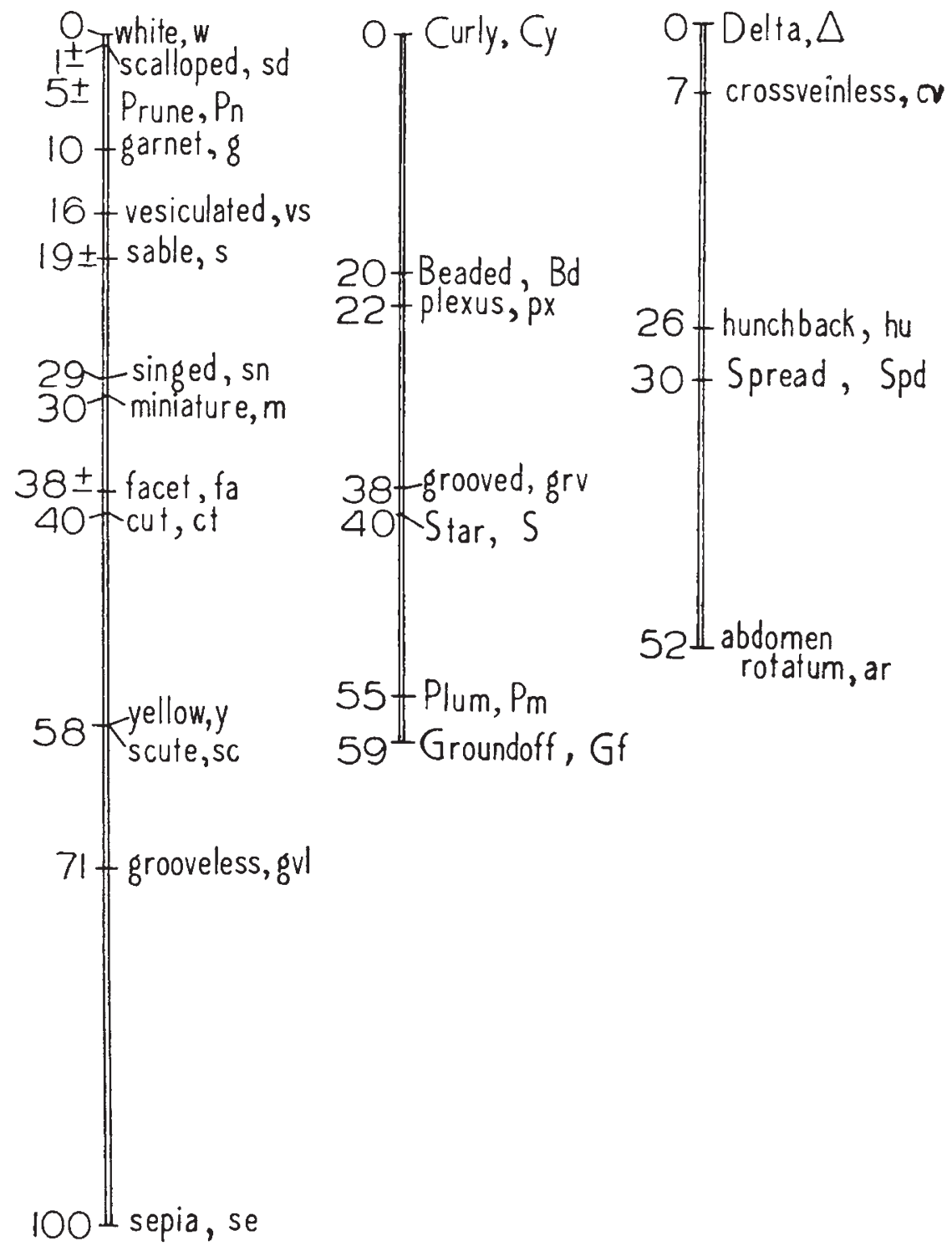

FIG. 2.-Linkage maps of the X-chromosome (left), second chromosome (middle), and third chromosome (right) of Drosophila prosaltans.

Examination of the data discloses a rather startling variability of the recombination percentages between the same genes in different experiments. Thus, the frequencies of recombination between yellow 
$(y)$ and miniature $(m)$ varied from $9 \cdot 7$ to $24 \cdot 3$ per cent. ; between singed $(s n)$ and white $(w)$ from $2 \cdot 1$ to 30.4 per cent. ; and between Star $(S)$ and Curly $(C y)$ from $16 \cdot 7$ to $4^{1} \cdot 6$ per cent. Since most of the mutants were induced by $\mathrm{X}$-ray treatments, a suspicion arose that the variability of the recombination percentages might be caused by chromosomal aberrations associated with the mutants. As indicated above, this suspicion proved to be justified in some cases ; the mutants involved were eliminated from the experiments. Other mutants seem to be free of major structural changes, as shown by examination of the chromosomes in the salivary gland cells made by Prof. Cavalcanti and ourselves. A high variability of recombination percentages in different strains seems to be characteristic of the species Drosophila prosaltans ( $c f$. Spurvay, 1945). In constructing the linkage maps, we concentrated our attention on finding the proper arrangement of the genes, and made rough estimates of the relative distances between them from variable data. The genes whose position relative to other known genes is uncertain are indicated by the \pm signs.

\section{DISCUSSION}

Some of the sex-linked mutants in Drosophila prosaltans resemble sex-linked mutants in other species of Drosophila so closely that it seems probable that changes in homologous genes are involved. Here belong white, singed, miniature, cut, yellow, scute and Notch. Scalloped, garnet, vesiculated, sable and facet may or may not be homologous to similarly named mutants in $D$. melanogaster (Bridges and Brehme, 1944; Sturtevant and Novitski, 194I ; Spurway, 1945). One sex-linked mutant in $D$. prosaltans, namely, sepia, parallels the sepia mutants which in $D$. melanogaster and $D$. simulans are autosomal and lie in the left limb of the third chromosome. Sepia is, however, sex-linked in $D$. pseudoobscura and $D$. persimilis. The situation is quite easily explained, since the species in which sepia is sex-linked have a large metacentric X-chromosome and those in which it is autosomal have a shorter acrocentric $\mathrm{X}$; the former species have three and the latter four autosomal strands in the salivary gland cells of male larvæ. The metacentric X-chromosome contains probably most of the genic materials which in species with acrocentric X's lie in one of the autosomes.

One of the sex-linked mutants in $D$. prosaltans, namely, grooveless, is almost certainly homologous to grooveless in $D$. melanogaster, the locus of which is in the small dot-like (fourth) autosome. The sexlinked Eyeless of $D$. prosaltans also resembles the Eyeless in the dot-like autosome of $D$. melanogaster. This situation is not entirely unexpected, since the species of the subgenus Sophophora which are native in the Neotropical zoogeographic region (i.e. the species of saltans and willistoni groups) lack the dot-like autosome which is present in most species of other sections of the genus. Sturtevant and Novitski (194I) 
conjectured that the genic materials of the dot-like autosome form in $D$. willistoni form a short "arm " attached to the same centromere as the approximately acrocentric third chromosome. This conjecture is not supported by the facts known in $D$. prosaltans, in which at least a part of the dot-like autosome is incorporated into the X-chromosome (see, however, the discussion of the genes in the third chromosome, below).

The second linkage group in $D$. prosaltans contains the mutants Curly, plexus, Star and Plum which are similar enough to the identically named mutants in the second chromosome of $D$. melanogaster to make probable that homologous loci are involved. Engrailed and Lobe are two further mutants which resemble second-chromosome mutants in $D$. melanogaster. The second chromosomes of the two species carry mostly similar materials. The mutant Beaded in the second chromosome of $D$. prosaltans resembles, however, Beaded in the right limb of the third chromosome of $D$. melanogaster. The resemblance is not close enough to insure homology, and the hypothesis that the second chromosome of $D$. prosaltans carries some materials located in $D$. melanogaster in the third chromosome cannot be accepted as proven.

The Delta mutant in the third linkage group of $D$. prosaltans resembles the Deltas in the right limbs of the third chromosomes of D. melanogaster and D. simulans, and Delta and Smoky in the second chromosomes of $D$. pseudoobscura and $D$. persimilis, all of which are presumed to be homologous. Crossveinless and Aristapedia of $D$. prosaltans are likely to be homologous respectively to crossveinless- $b$ and aristapedia, also in the right limb of the third chromosome of $D$. melanogaster, and hunchback is possibly homologous to the not precisely located third-chromosome mutant humped in $D$. melanogaster (Bridges and Brehme, I944, p. 93). Spread of D. prosaltans resembles spread which is supposed to lie in the left limb of the third chromosome of D. melanogaster (Bridges and Brehme, p. 178), and Blade is not unlike Dichaete in the same limb. The possibility must, therefore, be reckoned with that the third linkage group of $D$. prosaltans contains genes some of which lie in the right and others in the left limb of the third chromosome of $D$. melanogaster.

Most interesting is the abdomen rotatum mutant in the third linkage group of $D$. prosaltans. It is quite similar to abdomen rotatum mutants which are found in the dot-like autosomes of $D$. melanogaster, D. affinis, and $D$. virilis. In $D$. melanogaster abdomen rotatum is linked with grooveless and with Eyeless, which are in the X-chromosome of $D$. prosaltans (see above). The genic materials borne in the dot-like autosomes in $D$. melanogaster are, in $D$. prosaltans, divided between the $\mathrm{X}$ and the third chromosomes. The notion of indivisibility of the chromosome "elements" in the phylogeny of Drosophila is invalid (Sturtevant and Novitski, 194I).

The arrangement of the genes within the chromosomes of $D$. prosaltans will be discussed in the companion article of Spassky and Dobzhansky which deals chiefly with $D$. willistoni. 


\section{SUMMARY}

Drosophila prosaltans has three groups of linked genes which correspond to the three pairs of chromosomes present in its cells. These linkage groups have been compared to those of $D$. melanogaster. The sex-linked genes of $D$. prosaltans are of three kinds. Most of them correspond to genes borne in the X-chromosome of $D$. melanogaster; sepia is probably a homologue of the sepia mutant in the left limb of the third chromosome of D. melanogaster; and, finally, grooveless and Eyeless are borne in the dot-like autosome (fourth chromosome) of the latter species. The second chromosome of $D$. prosaltans corresponds to the second, and the third to the right limb of the third chromosome of $D$. melanogaster. However, the gene abdomen rotatum in the third linkage group of $D$. prosaltans is probably a homologue of the similarly named mutant in the fourth chromosome of D. melanogaster. Junction, fragmentation, and it seems also breakup and redistribution of gene aggregates, have taken place in the phylogeny of Drosophila.

\section{REFERENCES}

BRIDGES, C. B., AND BREHME, K. S. I 944 .

The mutants of Drosophila melanogaster.

Carnegie Inst. Washington, Publ. 552, I-257.

MORGAN, T. H., BRIDGES, C. B., AND STURTEVANT, A. H. 1925.

The genetics of Drosophila.

Bibliogr. Genetica, 2, 1-262.

RIDGWAY, R. I9I2.

Color standards and color nomenclature. Washington.

SPURWAY, H. I945.

The genetics and cytology of Drosophila subobscura. I. Element A.

J. Genet., 46, 268-286.

STUR TEVANT, A. H., AND NOVITSKI, E. I94I.

The homologies of the chromosome elements in the genus Drosophila.

Genetics, 26, 51 7-541. 